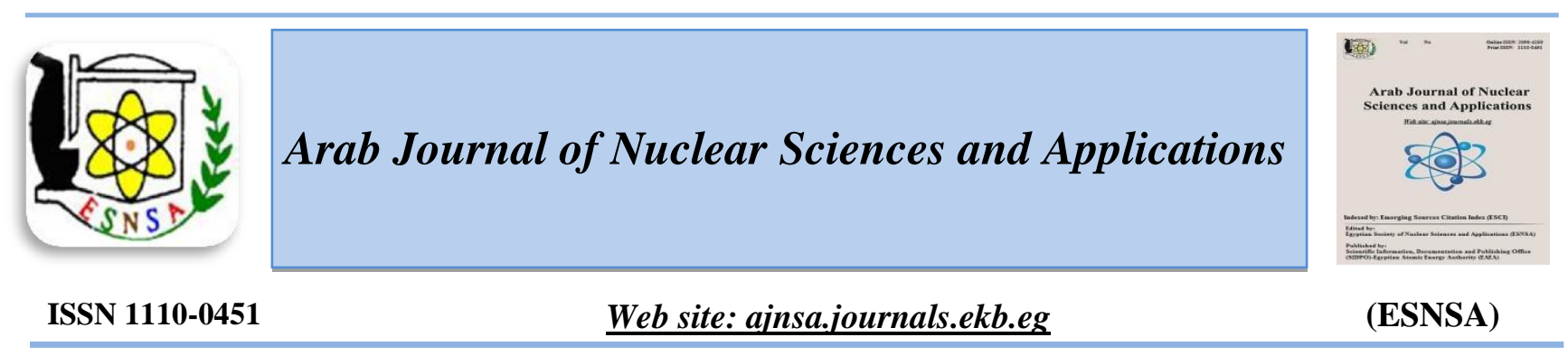

\title{
Selective Separation of Uranium and Thorium Using Mesoporous Modified Nano-Alumina from Abu Rusheid Leach Liquor
}

\author{
Abd Allh M. Abd El-Hamid \\ Nuclear Materials Authority (NMA), Cairo, Egypt.
}

\begin{abstract}
Received $17^{\text {th }}$ Dec. 2018 Accepted $17^{\text {th }}$ Mar. 2019

This study focuses on the synthesis and modification of mesoporous alumina monoliths in order to be used as a highly sensitive separating material for extraction of both U(IV) and Th (IV) ions selectively from real leach liquors. The adsorbent is prepared through functional immobilization of alumina with 2Amino-1-thia-3,4-diazole. TEM, $\mathbf{N}_{2}$ adsorption/desorption isotherm, TGA, and elemental analysis were carried out to demonstrate the fabricated mesoporous adsorbent. The optimum adsorption conditions such as $\mathrm{pH}$, time, and initial concentrations were investigated to study the adsorption behavior of the modified alumina for $\mathrm{U}(\mathrm{VI})$ and $\mathrm{Th}(\mathrm{IV})$. The obtained results demonstrate that, the adsorbent allow extremely efficient adsorption for $\mathrm{U}$ (VI) and Th(IV) ions at different pHs from the real matrix (Abu Rusheid, Egypt). The adsorption efficiencies of thorium and uranium are 80 and $85 \%$ respectively. The loaded thorium is eluted firstly by $6 \mathrm{M} \mathrm{HCl}$ then loaded uranium is eluted by $2 \mathrm{M} \mathrm{HNO}_{3}$. Moreover, the present study proved that for the separation of U (VI) and Th (IV) from sulfuric acid from Abu Rusheid leach liquor, alumina-ATDZ material should be used in about 3 stages of sequential separation.
\end{abstract}

Keywords: Mesoporous materials, Adsorption, Uranium, Thorium, Alumina

\section{Introduction}

From the economic perspective, energy represents a key element for the functioning of the global economy, being an important input to nearly all of the goods and services. In order to maintain and improve the living standards throughout the world, energy needs to be available and affordable.[1] To achieve that goal, continuing and reliable supplies of uranium are critical to nuclear power projects due to it is an inevitable mineral resource to produce the energy in atomic power plants [2]. In fact, uranium determination and separation from water, soil and other samples have therefore acquired a considerable importance. Hence, uranium is currently the preferred actinide in modern industries due to its use in power generation. It is also considered to be an ecologically toxic element [3]. While, the main sources of thorium in nature are soil, rock, plants, sand and water. Thorium has numerous uses in industry as well as being used as fuel for nuclear reactors [4]. ${ }^{233} \mathrm{U}$, which can be obtained by neutron capture and decomposition of ${ }^{232} \mathrm{Th}$, can be used as a nuclear fuel. Thorium is a possible nuclear fuel and the availability of thorium on the earth is 3-4 times more abundant than uranium [5]. Uranium and thorium are always associated with rare earth elements in different ores, especially monazite and bastnaesite [6].

Traditional methods for the extraction and separation of $U$ and $T h$ from rare earth elements suffer from solid and/or liquid waste disposal problems, as well as the significant loss of rare earth elements to waste [7, 8]. For this reason, in the past years, there has been a need for investigations studies containing different methods of separating $\mathrm{U}$ and $\mathrm{Th}$. In fact, solvent extraction

Corresponding author: abdallh.abdelhameed@hotmail.com

DOI: 10.21608 /ajnsa.2019.6727.1157

(C) Scientific Information, Documentation and Publishing Office (SIDPO)-EAEA 
and precipitations are the oldest common methods to efficiently remove uranium and thorium. On the other hand, solvent extraction is very costly if it is widely applied and leads to major environmental problems, the most important of which are toxic organic diluents. Besides, the use of flammable solvents makes solvent extraction very dangerous. Also, the application of precipitation in a complex system such as industrial wastewater makes it undesirable because of its extreme difficulty, high cost and consumption of time, as well as the contamination of uranium and thorium with the coprecipitated other metal ions, and this is one of the biggest obstacles [9]. Nowadays, there is an increasing interest in potential applications of adsorption technology in mineral separation, ore processing, water treatment and wastewater management, separation of metal ions. Therefore, there are considerable research activities in the study of new sorbents. Recently, a number of innovative adsorption materials have been developed and reported for the removal of uranium, thorium and heavy metal cations in general, from their aqueous solutions [10-18]. However, many anion exchange resins have been used to extract uranium and thorium ions from both strong acidic and basic solutions, although the most commonly used adsorbents for the extraction of these radionuclides are cation exchange ones $[19,20]$. For example, ion exchange has many advantages over traditional precipitation and organic solvent extraction. This is because direct precipitation involves low reallocation of rare earth elements, disposal of precipitation and contamination from radioactive deposit storage. It also has no common complication in solvent extraction, namely, loss of solvent, formation of third phase, effluent disposal problems, and phase separation [21].

The great invention of mesoporous materials has led to an urgent demand for new decorated adsorbents for metal ion separation. The immobilization of organic ligands onto inorganic substrate materials is of great benefits in various applications. Hence, mesoporous alumina is one of the most important and extensively used nonsiliceous mesoporous materials that offer a wide range of applications. Such applications include catalysis, sensors and separation. Their acidic surfaces, high surface area and tunable and uniform pore size make alumina versatile hosts for organic ligands. The mesostructured and high surface area of alumina render it to be used as an efficient substrate for simple immobilization and host for various organic molecules [1, 22]. Furthermore, the synthesis of mesostructured frameworks of alumina that show the ability of simple immobilization onto the interior mesopores remains a challenge. However, to control the successful decoration of substrates with large organic molecules without remaining attached to adsorbent surfaces, the synthesis of actively acidic alumina with uniform and large mesopores is a key requirement for good adsorbents for metal ions separations.

In the present study, mesoporous-adsorbent is prepared and successfully enabled a highly selective extraction of uranium and thorium ions by designing the 2-Amino-1-thia-3,4-diazole (ATDZ) ligand-doped nanoscale carrier of mesoporous network matrixes. The scope of the present investigation is to synthesize an innovative material having high selectivity adsorption for uranium and thorium ions from acidic sulfate media and to evaluate the potential application of this material to remove traces uranium and thorium ions from hydrometallurgical processing liquors. On the basis of the results here, the synthesized mesoporous material showed the sensitive extraction of uranium and thorium ions to a selective sequential separation with evidence of stability and selectivity in a rapid kinetic appreciation.

\section{Experiments \\ Chemicals}

All the chemicals and substances used in this study were used without additional purification because they were of analytical grade. Aluminum nitrate $\mathrm{Al}\left(\mathrm{NO}_{3}\right)_{3} \cdot 9 \mathrm{H}_{2} \mathrm{O}$, Polyoxyethylene (20) cetyl ether (Brij 58), $\mathrm{C}_{16} \mathrm{H}_{33}\left(\mathrm{OCH}_{2} \mathrm{CH}_{2}\right)_{2} \mathrm{OOH}$, (molecular weight average about $=1124$ ) and 2-Amino-1-thia3,4-diazole, $\mathrm{C}_{2} \mathrm{H}_{3} \mathrm{~N}_{3} \mathrm{~S}$ (ATDZ) which are obtained from Sigma-Aldrich Company Ltd. Dodecane was supplied by Alpha Aesar, Company Ltd. The U (IV), Th (IV) sulfates, $0.2 \mathrm{M} \mathrm{KCl-HCl,} \mathrm{and}$ $\mathrm{CH}_{3} \mathrm{COOH}-\mathrm{CH}_{3}-\mathrm{COONa}$ (acetate) buffer solutions used in the $\mathrm{pH}$ adjustment (1-6 range). $\mathrm{KCl} \&$ $\mathrm{CH}_{3} \mathrm{COONa}$ and $\mathrm{HCl} \& \mathrm{CH}_{3} \mathrm{COOH}$ and the other chemicals were from Sigma-Aldrich Inc., Missouri, United States and Fluka Chemical Corp. 
Synthesis of nano-alumina monolithic adsorbent The alumina synthesis was used on the basis of a direct template synthesis for the quaternary crystalline liquid microemulsion of the CTAB / dodecane / $\mathrm{Al}\left(\mathrm{NO}_{3}\right) / \mathrm{H}_{2} \mathrm{O}-\mathrm{HCl} /$ ethanol combination to form a nano-mesoporous alumina monolith [22]. (Scheme 1). The solution was diluted for 10 minutes consisting of the mixture $\mathrm{Al}\left(\mathrm{NO}_{3}\right)_{3}$, Brij 58, dodecane, $\mathrm{HCl}$ solution ( $\mathrm{pH}$ 1.3), and ethanol weight $15,2,0.5,2.5$ and $10 \mathrm{~g}$, respectively to form a homogeneous sol- gel solution. The liquid viscosity of the material increases with continuous fluxing and hydrolysis reactions / condensation for two hours until the material, similar to the resulting visual generation acquires the shape and size of the reaction vessel. The solid / surface alumina is completely dried at $40{ }^{\circ} \mathrm{C}$ overnight after large medium structures are formed and open due to the addition of the dodecane and ethanol swelling and co-coagulant agents under the continuous stirring. Then the organic fairness was removed by calcinations at $550{ }^{\circ} \mathrm{C}$ in air for 5 hours [22].

The alumina meso-adsorbent for uranium/thorium removal was prepared as follows: Mesoporous modified alumina adsorbent was prepared through the immobilization of 2-Amino-1-thia-3,4-diazole directly into $5 \mathrm{~g}$ of alumina prepared by monolith carrier. This was followed by impregnation under vacuum at $25{ }^{\circ} \mathrm{C}$ until chelating ligand saturation was achieved. Then a vacuum rotary evaporator was connected to get rid of ethanol and direct contact of the dye probe into the monoliths was occurred. The analysis of equilibrium adsorption capacity of the 2-Amino-1-thia-3,4-diazole molecules is spectrophotometrically performed with repeating the step of immobilization several times until reaching saturation. Finally, deionized water was used to wash the synthesized material adsorbent to no organic ligand elution was observed and drying at $65^{\circ} \mathrm{C}$ for $2 \mathrm{~h}$ was achieved.

\section{Characterization of alumina monolith adsorbent}

All available analyzes have been carried out to have complete description of the fabricated material such as FTIR, TGA, TEM, and Zeta potential. FTIR spectra were performed in $\mathrm{KBr}$ discs using Nexeus-Nicolite-Model 640-MSA.
FTIR, Thermo Electronics Co. (USA). ). X-Ray diffraction (XRD) analyses were carried out using a Philips X-ray generator model PW $3710=31$. Thermo-gravimetric analysis (TGA) was carried out using Shimadzu DT = TG-50 with a heating rate of $10^{\circ} \mathrm{C} / \mathrm{min}$. The particle size distribution of the modified alumina was evaluated through Dynamic Light Scattering (DLS). The zeta potential was measured using a Nano Series Zeta Sizer, Malvern; Worcestershire, the UK. The specific surface area, pore volume and the pore structure were determined utilizing the $\mathrm{N}_{2}$ adsorption technique using a BELSORP MIN-II analyzer (JP. BEL Co. Ltd) at 77 K. Highresolution transmission electron microscopy (HRTEM), was performed using a JEOL JEM model 2100F microscope, Japan.

\section{Batch experiments for adsorption of $U(V I)$ and Th (IV) ions}

In a typical uranium/thorium ion-adsorption experiments, $10 \mathrm{mg}$ of the fabricated modified alumina were mixed with $50 \mathrm{mg} / \mathrm{L}$ concentration of specific $\mathrm{U}$ or $\mathrm{Th}$ in invariable volume of $10 \mathrm{~mL}$ at the suitable $\mathrm{pH}$ (1-6). Then, a mechanical shaker was used for shaking the mixtures at $25{ }^{\circ} \mathrm{C}$ for the fitting time at $300 \mathrm{rpm}$ agitation speed. The mixture was filtered off after equilibrium achievement and the concerned metal residual concentration was spectrophotometrically determined applying Arsenazo III technique [23] and the adsorption capacity was calculate using the following equation;

$\mathrm{q}_{\mathrm{e}}=\left(\mathrm{C}_{\mathrm{i}}-\mathrm{C}_{\mathrm{e}}\right) \mathrm{V} / \mathrm{m}$

where $q$ represents the uptake $(\mathrm{mg} / \mathrm{g}), C_{i}$ and $C_{f}$ represent the initial and final metal ion concentrations $(\mathrm{mg} / \mathrm{L}), V$ be the volume (L) and $m$ represents the adsorbent weight $(\mathrm{g})$. 


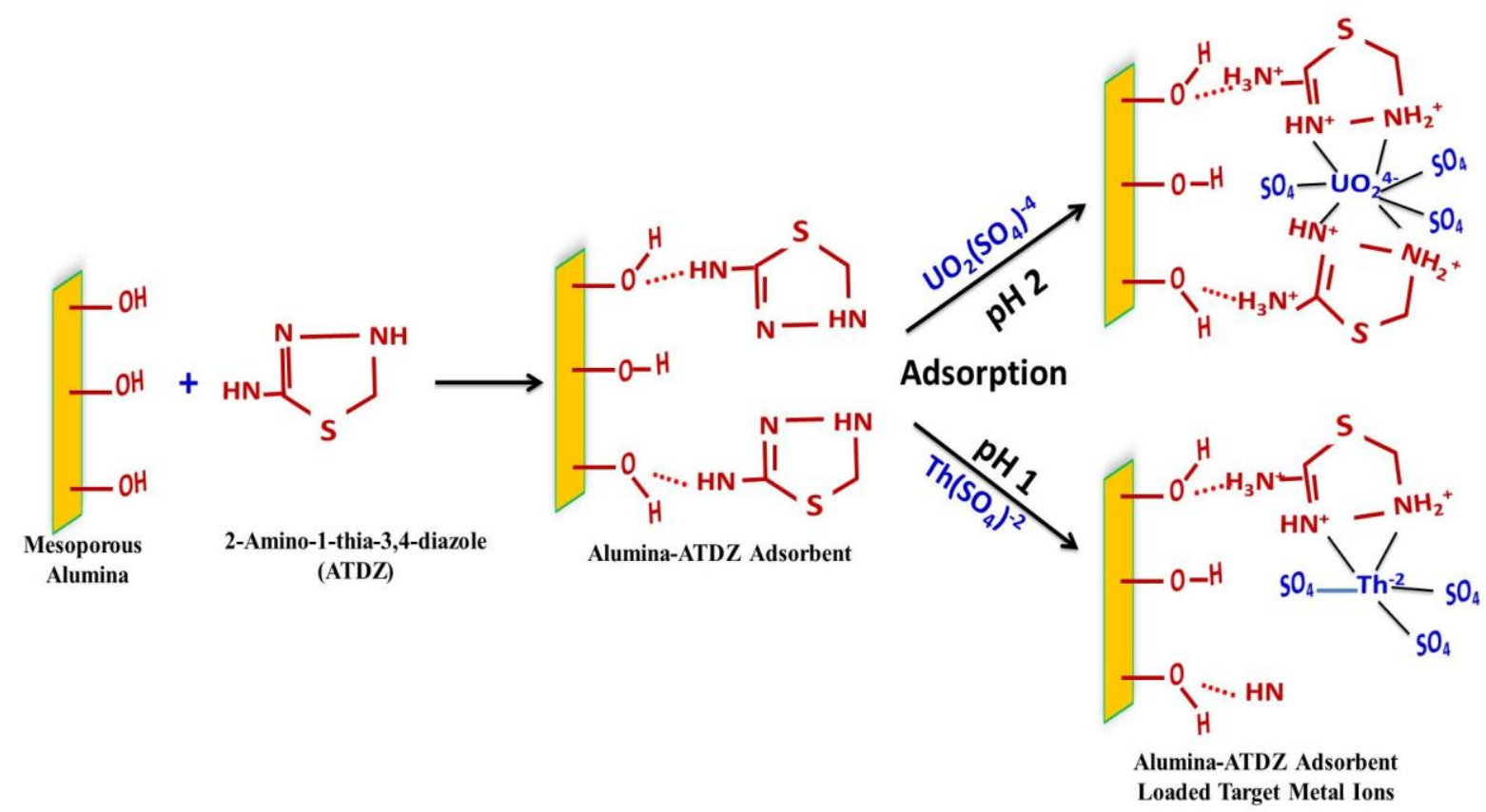

Scheme (1): Fabrication of the mesoporous alumina-ATDZ nano-adsorbent through the assisted pressure approach under vacuum at $25^{\circ} \mathrm{C}$ using rotary evaporator

\section{Results and Discussion}

\section{Characterization of Fabricated Monolith} Adsorbent

Mesoporous warm-like alumina meso-structures with regular and uniform cavities and porous entrance fissures were made-up directly using template liquid emulsion technique. The functional use of alumina with nano-scale size in a threedimensional structure was simply synthesized in terms of fabrication times and $\mathrm{Al} / \mathrm{Brij} 58$ ratio as shown in the high-resolution transmission electron microscope (HRTEM) images Fig. (1). The progress of disordered 3D structures feature, warm-like twisted and identical pore sizes, and Single - dispersion porous to nano-scale size (12 $\mathrm{nm}$ ) could effectively extend the applicability of alumina as carriers for an extract of $U$ and Th ions depending on the $\mathrm{pH}$ variations. TEM images Fig. (1) revealed that there are disordered mesoporous array over outsized areas of meso-adsorbent, in spite of the immobilization methods of the loading coverage of large organic molecules without steric hindrance. The HRTEM resulting images in Fig. (1) show clearly the attendance of a wormlike pore showing that the material has a mesoporous disordered structure.

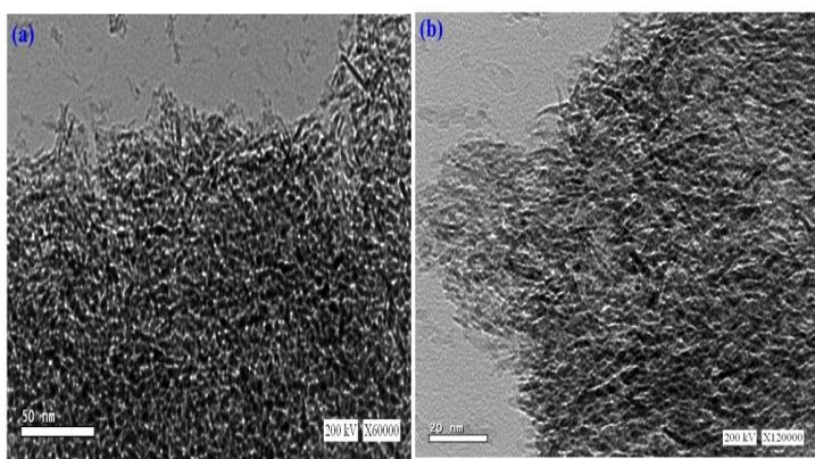

Figure (1): Representative HRTEM images show evidence of the formation of hexagonally warm like mesoporous structures

The FT-IR spectrum of the alumina- ATDZ and alumina- ATDZ loaded uranium results show that a number of distinctive bands are displayed, such as the band at 3450 which refers to the vibration stretching of $\mathrm{H}$-bonded of silanol group $v(\mathrm{Al}-$ $\mathrm{OH}$ ) alongside with water physisorbed molecules $v$ $(\mathrm{OH})$ ) also by the side with some bands occur at $3420,2925,2862,771$ which is an indicator of the presence of $v(\mathrm{~N}-\mathrm{H}), \quad v(-\mathrm{CH} 2), v(\mathrm{~S}-\mathrm{H})$, respectively. Also, other four bands come into sight at $1631,977,878,763 \mathrm{~cm}^{-1}$. These bands are 
assigned to $v(\mathrm{C}=\mathrm{N}), v(\mathrm{C}-\mathrm{N}), v(\mathrm{C}-\mathrm{H})$ and $v(\mathrm{C}-\mathrm{S})$ which are present in thiadiazole formation ring [1]. On the other hand, the $\mathrm{N}_{2}$ isotherms results show that ultimate type IV adsorption performance, with a well-known intelligent adsorption/desorption inflection Fig. (2b) and significant shifting of the adsorption branches toward lower relative pressure $\left(P / P_{0}\right)$ also is achieved. In addition, this fabricated material has great advantages, shown by the above results, which is the high surface area and the size of the large pores to increase the extraction efficiencies of U (VI) and Th (IV) from their leach liquors. The formations of uniformly-sized warmlike pores with pore openings about $12 \mathrm{~nm}$ are explained from isothermal shape and capillary evaporation. Moreover, our synthesized alumina feature surface area $\left(\mathrm{S}_{\mathrm{BET}}\right)$ of support material and modified with ATDZ was $198 \mathrm{~m}^{2} \mathrm{~g}^{-1}$, pore volume $\left(\mathrm{V}_{\mathrm{p}}\right)$ of alumina modified with ATDZ, were 0.30 $\mathrm{cm}^{3} \mathrm{~g}^{-1}$, respectively, and pore diameter (D) of alumina hold up material, modified with ATDZ was $12 \mathrm{~nm}$, respectively. The distribution of particle size to the synthesized alumina was determined using Dynamic Light Scattering (DLS) with sizes ranging from 70-90 nm Fig (2d).
Moreover, the thermo-gravimetric curves display weight losses of about $7.33 \%$ from modified alumina in the temperature range from 25 to $205^{\circ} \mathrm{C}$ and these losses correspond to the water physisorbed molecules as shown in Fig. (2c). Also, the higher weight loss in the temperature range 210.3-270.47 ${ }^{\circ} \mathrm{C}$ confirmed the occurrence of modification to the fabricated alumina adsorbent Fig. (2c). These weight losses correspond to material decomposition of the organic ligand of modified alumina. The observed weight loss in the temperature range $270.5-586.13{ }^{\circ} \mathrm{C}$ is attributed to the remaining organic matter of burned ATDZ. The DTA curve of modified alumina shows three well-pronounced endothermic peaks at 60,150 and $260{ }^{\circ} \mathrm{C}$. These endothermic peaks are due to the desorption of water and degradation of the organic matter. In addition, the obtained results proved that the alumina is thermally very stable up to $1000^{\circ} \mathrm{C}$ because no weight loss peaks are observed in the range $590-1000{ }^{\circ} \mathrm{C}$, Fig. (2b). Elemental analyses of the modified alumina give $6.74(\mathrm{C}), 2.26(\mathrm{H})$, $2.8(\mathrm{~S})$ and $7.92(\mathrm{~N}) \%$ for the modified alumina.
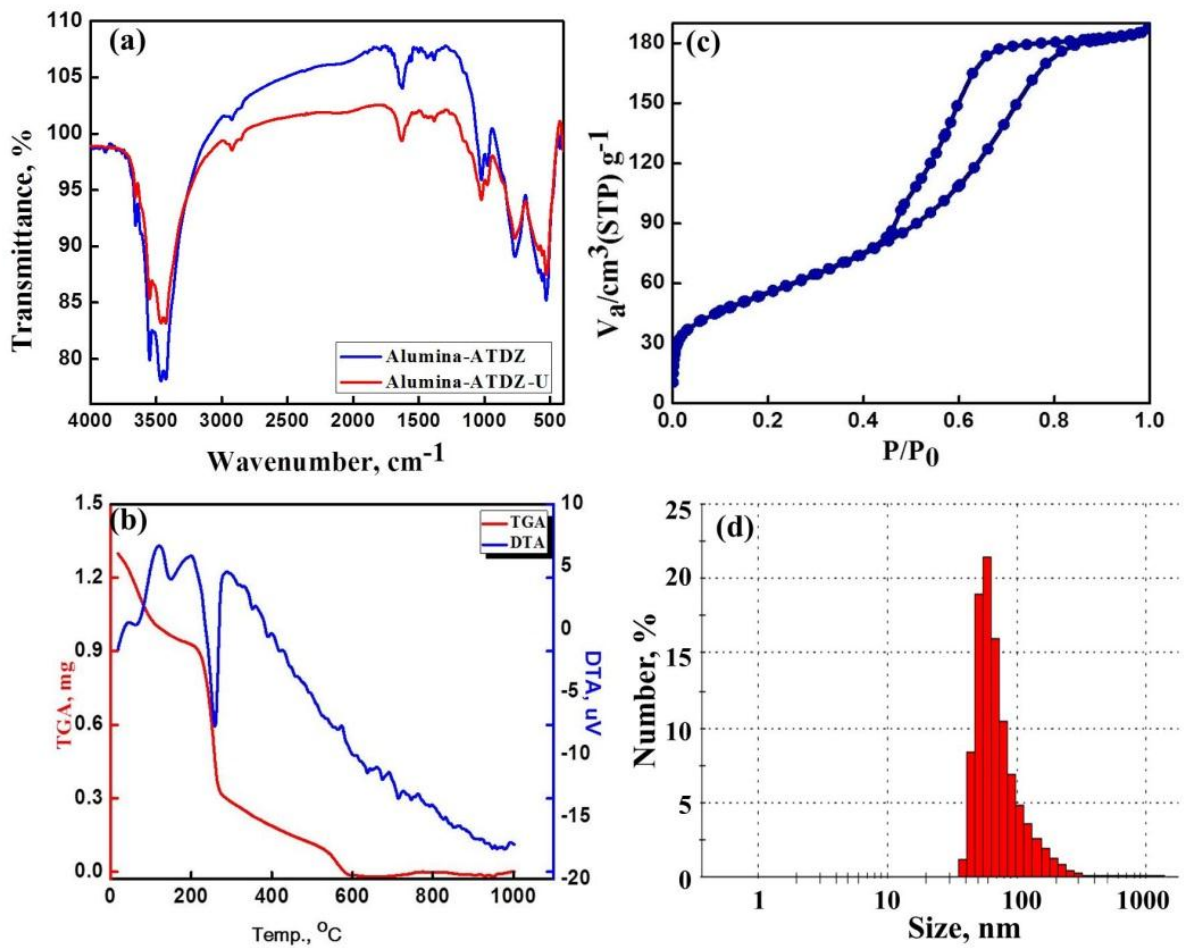

Figure ( 2 a): FTIR spectra for the synthesized alumina-ATDZ and uranium ions adsorbed on mesoporous alumina-ATDZ nanoparticles, (b) TGA and DTA, (c) $\mathbf{N}_{2}$ adsorption- desorption isotherm, and (d) particle size distribution of the mesoporous alumina-ATDZ nanoparticles 
Adsorption of $U$ (VI) on the fabricated mesoadsorbent

Effect of $\mathrm{pH}$

Thorium and uranium ion adsorption experiments were geared up in a $100 \mathrm{~mL}$ quartz flask. The thorium and uranium solutions were diluted from a $1000 \mathrm{ppm}$ aqueous stock standard solution into a flask at the appropriate $\mathrm{pH}(1-6)$ for $5 \mathrm{~min}$. In the present study, sets of experiments were performed in the form of batch contact-time to define and evaluate systematically the suitable conditions and the specificity of the synthesized meso-adsorbent towards $\mathrm{Th}\left(\mathrm{SO}_{4}\right)_{2}{ }^{2-}$ or $\left[\mathrm{UO}_{2}\left(\mathrm{SO}_{4}\right)_{3}\right]^{4-}$ ions which was controlled by means of $\mathrm{pH}$ adjustments. The adsorption procedure of $\mathrm{Th}\left(\mathrm{SO}_{4}\right)_{2}{ }^{2-}$ and $\left[\mathrm{UO}_{2}\left(\mathrm{SO}_{4}\right)_{3}\right]^{4-}$ ions on the mesoporous adsorbent was studied after equilibration. The obtained results, shown in Fig. (3a), revealed that the adsorbent is strongly susceptible in expressions of its high uptake and selectivity towards the $\mathrm{pH}$ of the $\left[\mathrm{UO}_{2}\left(\mathrm{SO}_{4}\right)_{3}\right]^{4-}$ or $\mathrm{Th}\left(\mathrm{SO}_{4}\right)_{2}{ }^{2-}$ ions solutions.

The effectiveness of the fabricated modified alumina-ATDZ for the adsorption of target metal ions was evaluated through quantitative studies at definite $\mathrm{pH}$ values Fig. (3a), to scientifically determine suitable $\mathrm{pH}$ conditions for the donor/acceptor combinations among AluminaATDZ as well the concerned metal ions. The highest uptakes value of $\mathrm{Th}\left(\mathrm{SO}_{4}\right)_{2}{ }^{2-}$ and $\left[\mathrm{UO}_{2}\left(\mathrm{SO}_{4}\right)_{3}\right]^{4-}$ ions were observed at $\mathrm{pH} 1$ and 2 respectively. The obtained of adsorption data Fig. (3a) show that uranium adsorption uptake increases with increasing the $\mathrm{pH}$ values then begins to decrease again after $\mathrm{pH} 2$ while the best results were conducted at $\mathrm{pH}$ of 2 . These results are in agreement with those obtained from Zeta potential measurements Fig. (3b), which reveals that the zero charges point $(p z c)$ is about $\mathrm{pH}$ 5.9. The shift in the $p z c$ to a higher $\mathrm{pH}$, relative to the $p z c$ of pure alumina supports indicate the probability of immobilization of the chelating moiety (ADTZ) occurrence to alumina surface. This may be attributed to the decrease of the negative charge generated from the dissociation of $\mathrm{OH}$ of alumina surface [24]. Below the $p z c$ of alumina-ADTZ, the $\mathrm{N}$ sites become protonated $\left(\mathrm{NH}^{+}\right)$and the surface charge of the particles tends to be positive and increases as the $\mathrm{pH}$ decreases. Above $\mathrm{pH}$ 5.9, the measurements showed negative values of zeta potential. This may be attributed to the dissociation of the -SH groups contained on the alumina-ATDZ surface giving $\left(-S^{-}\right)$and consequently its basic character increases [25]. Hydrogen ion concentration plays an important role in uranium adsorption on an anion exchanger that at $\mathrm{pH}$ values below 1.5 there is no sufficient $\mathrm{SO}_{4}{ }^{2-}$ ions to furnish the uranium sulfate complexes since $\mathrm{HSO}_{4}{ }^{-}$ions are the main. In addition, the uranium uptake from sulfate solution is a character of $\mathrm{SO}_{4}{ }^{2-}$ concentration due to the influence of uranium anion formed under equilibrium conditions. As a matter of fact, the uranium uptake is favored until the ratio of $\left(\mathrm{SO}_{4}\right)^{2-}$ $/[\mathrm{U}]$ is less than 2 but if this ratio increases above 2 , the uranium uptake decreased. This is why the excess $\mathrm{SO}_{4}{ }^{2-}$ compete with the uranium complex for active sites. In fact, uranium exists in the sulphate solutions as an uncharged $\mathrm{UO}_{2}\left(\mathrm{SO}_{4}\right)$ complex, and the anionic $\left[\mathrm{UO}_{2}\left(\mathrm{SO}_{4}\right)_{2}\right]^{2-}$ and $\left[\mathrm{UO}_{2}\left(\mathrm{SO}_{4}\right)_{3}\right]^{4-}$ complexes due to the amount of $\left(\mathrm{SO}_{4}\right)^{2-}$ ion in the media which can also be adsorbed [26]. On the other side, the obtained results of thorium adsorption proved that the highest efficiency of thorium adsorption is at $\mathrm{pH}$ value of 1 which reaches about $52.1 \%$ then decreases again and both of uranium and thorium begin to precipitate at a $\mathrm{pH}$ value higher than 5 . Generally, thorium and uranium react with sulfuric acid and form thorium and uranium sulfate according to the following equations:

$\mathrm{UO}_{2}{ }^{2+}+3\left(\mathrm{SO}_{4}\right)^{2-} \rightarrow \mathrm{UO}_{2}\left(\mathrm{SO}_{4}\right)_{3}{ }^{4-}$

$\mathrm{Th}^{4+}+2\left(\mathrm{SO}_{4}\right)^{2-} \rightarrow \mathrm{Th}\left(\mathrm{SO}_{4}\right)_{2}^{2-}$

The obtained results have shown that the adsorption progression of the composite material is fundamentally dependent on acid concentration. Also, 2 sequential stages are sufficient to complete selective separations of uranium and thorium from sulfate solution.

\section{Effect of Contact Time}

The effect of contact time on the adsorption of target metal ions at room temperature and $\mathrm{pH}=1,2$ for Th and $\mathrm{U}$ respectively, is illustrated in Fig. (4). Within $10 \mathrm{~min}, \mathrm{Th}\left(\mathrm{SO}_{4}\right)_{2}{ }^{2-}$ and $\left[\mathrm{UO}_{2}\left(\mathrm{SO}_{4}\right)_{3}\right]^{4-}$ the uptake represents 93 and $81 \%$ at the plateau, respectively. The equilibrium was attained within 10 and $15 \mathrm{~min}$ for $\mathrm{Th}\left(\mathrm{SO}_{4}\right)_{2}{ }^{2-}$ and $\left[\mathrm{UO}_{2}\left(\mathrm{SO}_{4}\right)_{3}\right]^{4-}$, respectively. Moreover, the pseudo-second-order model is applied to explain the adsorption kinetics, according to equation 4 [16]; 
$t /\left(q_{t}=1 / k_{2} q_{e}{ }^{2}\right)+t / q_{e}$

Where $k_{2}$ represents overall rate constant of the pseudo-second order $(\mathrm{g} / \mathrm{mg} \mathrm{min}$ ) by plotting $t / q t$ versus $t$ as shown in fig.4a. The obtained results clearly show that there is an adequate harmony between the calculated and experimental values of $q_{e}$ which means that the adsorption process progresses obeying a pseudo-second order kinetics Fig. (4b).

\section{Adsorption isotherms}

In fact, there are many theories and different precise equations that have been recommended for adsorption isotherm studies, Adsorption data of uranium and thorium are analyzed applying the linear form of both Langmuir and Freundlich isotherms. The initial concentrations of the concerned metal ions effect on their uptake capacity are studied and the obtained results are based on the application of the Langmuir adsorption isotherm Fig. (4d), according to the following equation 5 [27]

$C_{e} / q_{e}=1 / K_{l} q_{m}+C_{e} / q_{m}$ where $q_{m}$ represents amount of metal ions adsorbed to form monolayer reporting $(\mathrm{mg} / \mathrm{g})$ and $K_{L}$ is the Langmuir adsorption equilibrium constant. The latter two values $q_{\mathrm{m}}$ and $K_{\mathrm{L}}$ were obtained from the slope and intercept respectively, of the linear areas of the Langmuir plot (Fig. 4d). It is clear from the obtained data that the equilibrium uptake capacity increases with increasing the initial metal ions concentration. In addition, the obtained straight line of the Celqe against $\mathrm{Ce}$ plot of this adsorption attempt reveals the formation of the monolayer treatment of metals on the meso-adsorbent of alumina-ATDZ interior pore surfaces. For illustration, the obtained $q_{m}$ data results indicated that the practical extraction of the concerned metal ions from the sulfate medium with high uptake efficiencies reaches $96-98 \%$ from dilute solutions. Thus, the extraction of $1 \mathrm{~g}$ of both $\mathrm{Th}\left(\mathrm{SO}_{4}\right)_{2}{ }^{2-}$ and $\mathrm{UO}_{2}\left(\mathrm{SO}_{4}\right)_{2}{ }^{2-}$ from an sulfate solution would involve about 10 and $11 \mathrm{~g}$ of Alumina-ATDZ respectively. In addition, the values of $K_{L}$ values are accepted with the adsorption/desorption rates, which represents completely reversible metal adsorption assays. The comparison of the adsorption capacities of uranium and thorium onto our fabricated adsorbent with various adsorbents are listed in Table (1).
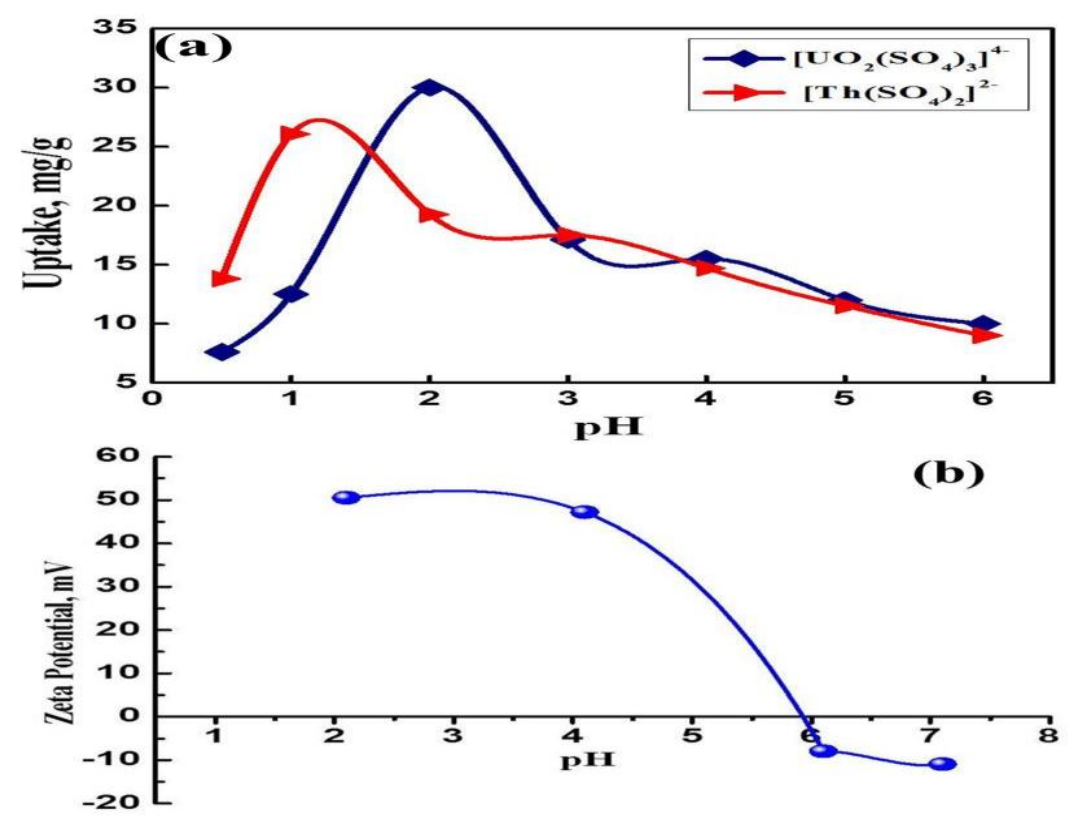

Figure (3): (a) Effect of $\mathrm{pH}$ upon $\mathrm{U}$ and Th adsorption by Alumina-ADTZ; initial metal concentration $50 \mathrm{mg} / \mathrm{L}$, aluminaATDZ weight $10 \mathrm{mg}$, solution volume $10 \mathrm{~mL}$, contact time $20 \mathrm{~min}$ at $25^{\circ} \mathrm{C}$ and (b) Zeta potential of Mesoporous- aluminaATDZ 

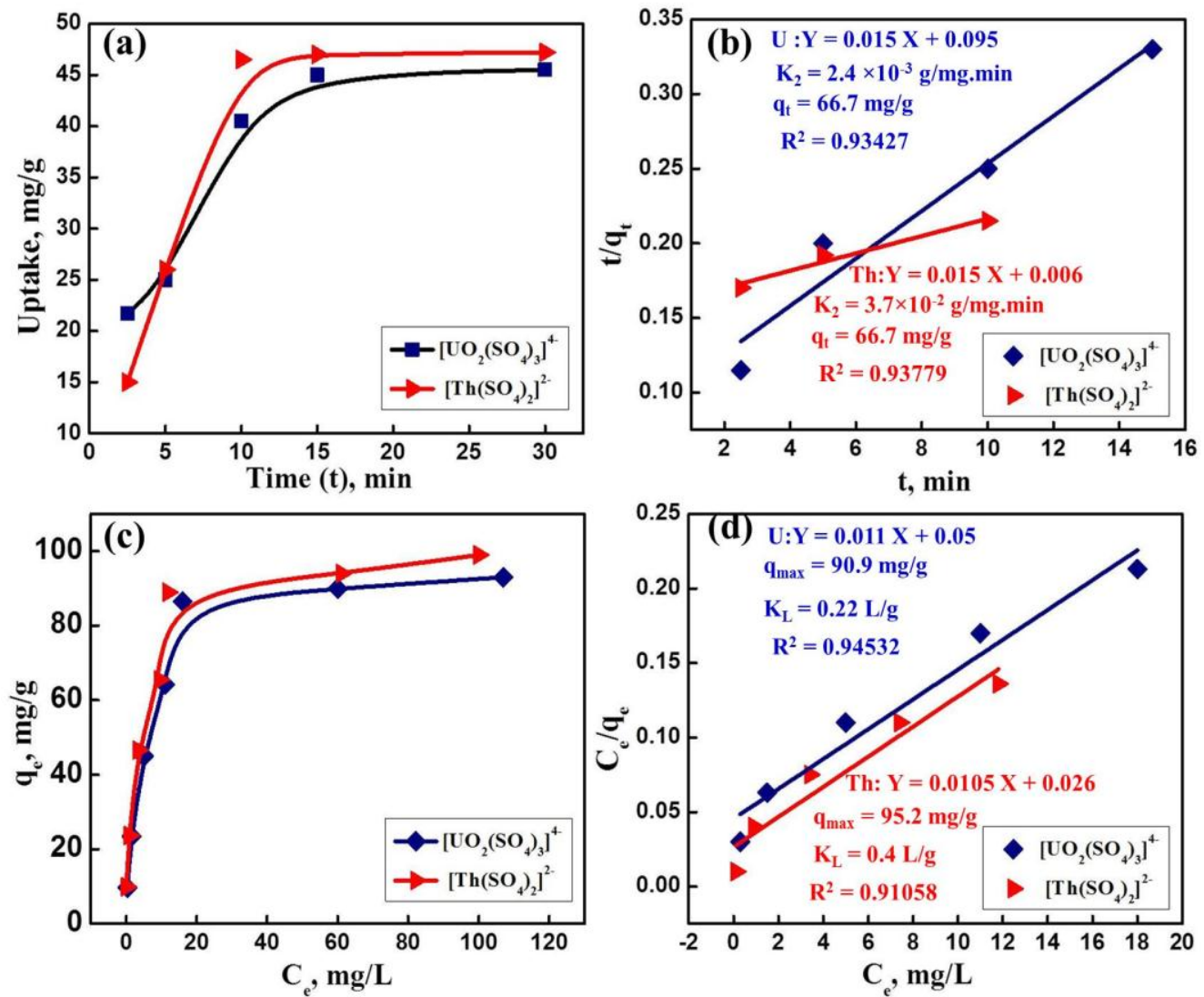

Figure (4): (a) Effect of contact time on $U$ and Th adsorption by Alumina-ADTZ from individual ion solution, (b) the pseudo-second-order plot at the optimal adsorption conditions. (c) Adsorption isotherm of the adsorption of $U$ and $T h$ ions on Alumina-ADTZ from a single ion solution, and (d) Langmuir scheme of $U$ and Th uptake by Alumina-ADTZ at the optimum conditions.

Table (1): Comparison of the adsorption capacities of uranium and thorium onto various adsorbents

\begin{tabular}{|c|c|c|c|c|}
\hline \multirow{2}{*}{ Carrier } & \multirow{2}{*}{ Ligand } & \multicolumn{2}{|c|}{ Uptake, mg/g } & \multirow{2}{*}{ Ref. } \\
\hline & & $\mathbf{U}(\mathbf{V I})$ & Th(IV) & \\
\hline Aluminosilica & 2-Amino-1,3,4-thiadiazole & 83.30 & --- & [1] \\
\hline Silica & Tetraethylene-pentamine & 112.00 & 96.00 & {$[2,4]$} \\
\hline XAD & Carminic acid & 194.05 & 194.96 & [30] \\
\hline Graphene aerogel & $\mathbf{N}, \mathbf{N}, \mathbf{N}^{\prime}, \mathbf{N}^{\prime}$-tetraoctyldiglycolamide & --- & 66.8 & [31] \\
\hline Activated carbon & Polyethylenimine & 115.31 & --- & [32] \\
\hline SBA-15 & Thenoyltrifluoroacetone & --- & 39.8 & [33] \\
\hline Chitosan & Triethylene-tetramine & --- & 133.3 & [34] \\
\hline Silica & Humic acid & 31.3 & 28 & [35] \\
\hline SBA-15 silica & Ethylenediaminepropylesalicylaldimine & 105.3 & 81 & [36] \\
\hline Silica & 3-aminopropyl trimethoxysilane & 268.94 & --- & [37] \\
\hline Silica & Sulfasalazine & 273.7 & -- & [38] \\
\hline Alumina & 2-Amino-1-thia-3,4-diazole & 90.9 & 95.2 & [This work] \\
\hline
\end{tabular}




\section{Real applicability}

Abu Rasheid locality is considered one of the promising areas for containing various mineralizations of such important elements such as rare earth elements, uranium and thorium. The location of Abu Rasheid is about $50 \mathrm{~km}$ away from Marsa Alam and located southeast of Egypt between the longitudes 34 and 46'00 "34-46'35" E and the latitudes $24^{\circ} 37^{\prime} 16^{\prime \prime}-24^{\circ} 38$ '00 'N, [28]. A leaching experiment was carried out to about 0.5 $\mathrm{kg}$ of a representative sample obtained from $\mathrm{Abu}$ Rusheid locality applying the optimum leaching conditions applied by Afify et al., (2018) [29], with some modification to prepare the leach liquor for studying the ability of the concerned material in the extraction separation of uranium and thorium. The applied optimum leaching conditions are $100 \mathrm{~g} / \mathrm{L} \mathrm{H}_{2} \mathrm{SO}_{4}$ acid with a solid/liquid ratio of $1 / 5$ for $2 \mathrm{~h}$ agitation time at $90{ }^{\circ} \mathrm{C}$ leaching temperature with -200 mesh grain size. The leaching system is then filtered off after cooling and the obtained leach liquor has a concentration of uranium and thorium of 570 and 685 ppm respectively and the concentrations of other impurities present with uranium and thorium in the leach liquor are given in Table (2). The obtained leach liquor $\mathrm{pH}$ is adjusted at 1 using ammonia solution, and applied the thorium adsorption conditions of $10 \mathrm{~min}$. contact time at room temperature then the $\mathrm{pH}$ raised to 2 and contact time to $15 \mathrm{~min}$ at room temperature also to remove uranium with solid/liquid ratio of 10 . The obtained data revealed that the adsorption efficiencies of thorium and uranium are 80 and $85 \%$ respectively, and the separation of the two concerned metal ions achieved sequentially. The loaded thorium and uranium are then eluted applying the elution conditions used by Iyer et al., (1977) [29] that thorium is eluted firstly using $6 \mathrm{M} \mathrm{HCl}$ then uranium is eluted by $2 \mathrm{M} \mathrm{HNO}_{3}$. Finally, this study proved that for the complete separation of U (VI) and Th (IV) from sulfuric acid of Abu Rusheid leach liquor, this needs about 3 stages of sequential separation using alumina-ATDZ material.

\section{Conclusions}

Alumina in the worm-like mesoporous architecture was used as stage substrate to produce an economically inexpensive anion exchanger material that is effective and useful in selective extraction of $\mathrm{Th}\left(\mathrm{SO}_{4}\right)_{2}{ }^{2-}$ and $\mathrm{UO}\left(\mathrm{SO}_{4}\right)_{2}{ }^{2-}$ from its solutions. The design-made meso-adsorbent, through the direct immobilization of 2-Amino-1thia-3,4-diazole ligand onto worm like mesoporous carriers, enabled the creation of selective extraction of thorium and uranium from real leach liquor under specific $\mathrm{pH}$ values. This study has demonstrated the ease of applying this technology on a large scale through the promising results achieved $\mathrm{Th} / \mathrm{U}$ separation.

Table (2): chemical composition of Abu Rusheid leach liquor

\begin{tabular}{c|ccc}
\hline $\begin{array}{c}\text { Metal } \\
\text { Conc., (ppm) }\end{array}$ & $\begin{array}{c}\text { Abu Rusheid } \\
\text { leach liquor }\end{array}$ & $\begin{array}{c}\text { After Th } \\
\text { adsorption }\end{array}$ & After U adsorption \\
\hline U & 570 & 475 & 72 \\
Th & 685 & 136 & 105 \\
Fe & 789.3 & 701 & 586 \\
Ca & 505.8 & 504 & 414 \\
Co & 7.8 & 6 & 2.8 \\
Cu & 380 & 375 & 357 \\
Ni & 19.4 & 19.4 & 19.4 \\
Zn & 425.2 & 423 & 423 \\
Mo & 28 & 26 & 18 \\
Cd & 2 & 2 & 2 \\
As & 125 & 124 & 120 \\
Pb & 7.2 & 7.2 & 6.5 \\
Mg & 47.6 & 44 & 35 \\
Cr & 7.3 & 5 & 3.3 \\
\hline
\end{tabular}




\section{Acknowledgements}

The author express thanks to the colleagues of the Yellow Cake Purification, Pilot Plant Experiments, and Chemical Analysis Departments especially Inductively Coupled Plasma Lab. which contributed in conducting analyzes control of this work and also for their sincere and useful assistance

\section{References}

1- Emad A. Elshehy. (2017), Removal of uranium ions from liquid radioactive waste using modified aluminosilica. Separation Science and Technology. 52 (11), 1852-1861

2- Donia A. M., Atia A. A., Daher A. M., Desouky O. A., and Elshehy E. A. (a) (2011), Selective separation of U (VI) from its solutions using amine modified silica gel produced from leached zircon, International Journal of Mineral Processing 101, 81-88,

3- Manjusha Karve and Kinny Pandey. (2010), Cyanex272 impregnated on Amberlite XAD-2 for separation and preconcentration of U (VI) from uranmicrolite (leachates) ore tailings, J. Radioanal. Nucl. Chem. 285:627-633

4- Donia A. M., Atia A. A., Daher A. M., Desouky O. A., and Elshehy E. A. (b) (2011), Selective separation of Th (IV) from its solutions using amine modified silica gel produced from leached zircon, J. Radioanal. Nucl. Chem. 290:297-306,

5- Yanliang Chena, Yuezhou Weia, Linfeng Heb, Fangdong Tang. (2016), Separation of thorium and uranium in nitric acid solution using silica based anion exchange resin TangbaSchool Journal of Chromatography 1466, 37-41.

6- Kwang Loon Ang, Dan Li, Aleksandar N. Nikoloski. (2017), The effectiveness of ion exchange resins in separating uranium and thorium from rare earth elements in acidic aqueous sulfate media. Part 1. Anionic and cationic resins, Hydrometallurgy 174, 147-155

7- Gui W., Zhang H., Liu Q., Zhu X., Yang Y., (2014), Recovery of Th (IV) from acid leaching solutions of bastnaesite at low concentrations. Hydrometallurgy 147-148, 157-163.

8- Zhu, Z., Pranolo, Y., Cheng, C.Y. (2015), Separation of uranium and thorium from rare earths for rare earth production - a review. Miner. Eng., 77, 185-196.

9- Abolfazl Rahmani-Sani, Ahmad HosseiniBandegharaei, Seyyed-Hossein Hosseini, Keivan Kharghani, Hossein Zarei, Ayoob Rastegar. (2015), Kinetic, equilibrium and thermodynamic studies on sorption of uranium and thorium from aqueous solutions by a selective impregnated resin containing carminic acid, Journal of
Hazardous Materials 286, 152-163

10- Olmez Aytas S., S. Akyil, M. Eral, (2004), Adsorption and thermodynamic behavior of uranium on natural zeolite, J. Radioanal. Nucl. Chem. 260, 119-125.

11- Shahwan T., H.N. Erten, (2005), Characterization of $\mathrm{Sr} 2+$ uptake on natural minerals of kaolinite and magnetise using XRPD SEM/EDS, and DRIFT, Radiochim. Acta 93, 225-232.

12- Atia A.A., (2005), Studies on the interaction of mercury (II) and uranyl with modified chitosan resins, Hydrometallurgy 80, 13-22.

13 Prabhakaran D., Subramanian M.S., (2005), Selective extraction of U (VI) over Th (IV) from acidic streams using di-bis(2-ethylhexyl) malonamide anchored chloromethylated polymeric matrix, Talanta 65, 179-184.

14- Shehata F.A., M.F. Attallah, E.H. Borai, M.A. Hilal, M.M. Abo-Aly, (2010), Sorption reaction mechanism of some hazardous radionuclides from mixed waste by impregnated crown ether onto polymeric resin, Appl. Radiat. Isot. 68, 239249.

15- Vivero-Escoto L., M. Carboni, C.W. Abney, K.E. deKrafft, W. Lin, (2013), Organofunctionalized mesoporous silicas for efficient uranium extraction, Microporous Mesoporous Mater. 180, 22-31.

16- Sadeek S.A., E.M.M. Moussa, M.A. El-Sayed, M.M. Amine, M.O. Abd El-Magied, (2014), Uranium (VI) and thorium (IV) adsorption studies on chelating resin containing pentaethylenehexamine as a functional group, J. Disp. Sci. Technol. 35 926-933.

17- Shao D., G. Hou, J. Li, T. Wen, X. Ren, X. Wang, (2014), PANI/GO as a super adsorbent for the selective adsorption of uranium(VI), Chem. Eng. J. 255, 604-612

18- Zhao Y., J. Li, S. Zhang, X. Wang, (2014), Amidoxime-functionalized magnetic mesoporous silica for selective sorption of U(VI), RSC Adv. 62, 3271-32717.

19- Nisa Q., A. Ali, M. Haleem Khan (2013), FIspectrophotometric determination of uranium after preconcentration on an anion exchange resin, J. Radioanal. Nucl. Chem. 295, 2203-2214.

20- Solgy M., M. Taghizadeh, D. Ghoddocynejad, (2015). Adsorption of uranium (VI) from sulphate solutions using Amberlite IRA-402 resin: Equilibrium, kinetics and thermodynamics study, Ann. Nucl. Energy 75, 132-138.

21- Wang, L., Yu Y., Huang X., Long Z., Cui D (2013),. Toward greener comprehensive utilization of bastnaesite: simultaneous recovery of cerium, fluorine, and thorium from bastnaesite leach liquor using HEH (EHP). Chem. Eng. J. 215-216, 162-167. 
22- Sherif A. EL-Safty, M. Khairy, and M. Ismael (2012). Nanoadsorbent of Organic Compounds Based on Two- and Three Dimensional Mesocylinder Monoliths. Journal of Environmental \& Analytical Toxicology. 2 (5), 18

23- Marczenko Z. Separation and spectrophotometric determination of elements. 2nd edn. Ellis Harwood, Chichester, (1976)

24- Adegbite S. (2013),. Particle Characterisation and Grinding Behaviour of Gamma-Alumina Slurries Prepared in a Stirred Media Mill, Journal of Materials Science Research. 2 (1) 135-147.

25- Irving R. J., L. Nelander, I. Wadso, (1964). Thermodynamics of the ionizations of some thiols in aqueous solutions, Acta Chemical Scandinavica, 18, 769-787.

26- Fathi Habashi, Laval University, Quebec City, Canada. (1993).

27- Zaki D.I., Shawky N., El-Sheikh E.M., Ahmed F.Y., and Ibrahim M.E. (2012), Recovery of some valuable elements from lamprophyre dykes in the Abu Rusheid area, Southeastern Desert, Egypt. Chin. J. Geochem. 31, 064-073

28- Afifi, S. Y., Saad, M. Z., Yousef L. A, Ismail A. H., (2018), Leaching and Precipitation of Thorium Ions from Cataclastic Rocks, Abu Rusheid Area, South Eastern Desert, Egypt. Arab Journal of Nuclear Sciences and Applications. 51, (2), $10-19$

29- Ganapathy Iyer S., Padmanabhan P. K., and Venkateswarlu CH. (1977). Use of Dowex A$\mathrm{I}(\mathrm{H}+)$ and ZeoKarb 226(H+) for the Sequential Separation of Uranium, Thorium, and Rare Earths in Monazite. Separation Science, 12(2), 205-210

30- A. Rahmani-Sani, A. Hosseini-Bandegharaei, . HosseinibK. Kharghani, I, H. Zarei A.Rastegar (2015). Kinetic, equilibrium and thermodynamic studies on sorption of uranium and thorium from aqueous solutions by a selective impregnated resin containing carminic acid, J. Hazard. Mater., 286, 152-163.

31- Chen, M., Li, Z., Geng, Y., Zhao, H., He, S., Li, Q., Zhanga L. (2018). Adsorption behavior of thorium on N,N,N,N'-tetraoctyldiglycolamide (TODGA) impregnated graphene aerogel, Talanta 181, 311-317.

32- Naeemullah, T.S., Tuzenbd, M., Sarı, A. (2017).Polyethylenimine modified activated carbon as novel magnetic adsorbent for the removal of uranium from aqueous solution, Chemical Engineering Research and Design, 117, 218-227

33- Gök, M., Sert, Ş., Özevci, G. Efficient adsorption of Th(IV) from aqueous solution by modified SBA-15 mesoporous silica, Nucl Sci. Tech. (2018) 29:95

34- Xu, J., Zhou, L., Jia, Y. et al. (215). Adsorption of thorium (IV) ions from aqueous solution by magnetic chitosan resins modified with triethylene-tetramine, J Radioanal Nucl Chem 303, 347-356.

35- Prasetyo, E., Toyoda, K., (2017) Solid Phase Extraction of Thorium and Uranium and their Separation from Lanthanides using Humic Acid Silica Gel as a Low-Cost Adsorbent. Eng. Technol. Sci., 49( 4) 508-519.

36- Dolatyari, L., Yaftian, M., Rostamnia, S. (2016). Removal of uranium(VI) ions from aqueous solutions using Schiff base functionalized SBA15 mesoporous silica materia, J. Environmental Management, 169, 2016, 8-17.

37- Dolatyari, L., Yaftian, M., Rostamnia, S., (2016). Adsorption characteristics of Eu(III) and Th(IV) ions onto modified mesoporous silica SBA-15 materials, $\underline{J}$. the Taiwan Institute of Chemical Engineers, 60, 174-184.

38- S. Sadeghi, E. Sheikhzadeh, (2009). Solid phase extraction using silica gel modified with murexide for preconcentration of uranium (VI) ions from water samples, J.Hazard. Mater., 163, 861-868

39- S. Sadeghi, E. Sheikhzadeh, Solid phase extraction using silica gel functionalized with Sulfasalazine for preconcentration of uranium(VI) ions from water samples, Microchim Acta (2008) 163: 313. 